\title{
Bigger testes do work more: experimental evidence that testis size reflects testicular cell proliferation activity in the marine invertebrate, the free-living flatworm Macrostomum sp.
}

Received: 6 January 2004 / Revised: 30 March 2004 / Accepted: 15 April 2004 / Published online: 26 May 2004 (C) Springer-Verlag 2004

\begin{abstract}
Evolutionary theory predicts that more resources are allocated to sperm production when sperm competition is high. This prediction is supported by both comparative and experimental data on static measures of male allocation, such as testis and ejaculate size. However, resource allocation is a dynamic process, and it is therefore important to evaluate if the static measures reflect this. Such an evaluation has to our knowledge never been done. Immunocytochemical labelling with bromodeoxyuridine (BrdU) allows visualisation of cells in S-phase. BrdU becomes incorporated into cells if, and only if, they are actively undergoing DNA duplication, which is a dynamic process. The number of BrdU-positive cells in the testis can hence serve as a dynamic measure of male allocation, i.e. testicular activity. We evaluate the relationship between testis size and testicular activity in the marine flatworm Macrostomum sp. In a previous study, we showed that testis size is phenotypically plastic in this species, and that worms make larger testes when they are raised in larger groups. We use this plasticity to experimentally produce variation in testis size, and demonstrate that larger testes are associated with higher testicular activity. Moreover, testis size and testicular activity were related linearly. We have thus, for the first time, shown that testis size is a good measure of resource allocation to the male function. Moreover, increased testicular activity is probably one of the first steps in the
\end{abstract}

Communicated by N. Wedell

L. Schärer $(\bowtie) \cdot$ P. Ladurner · R. M. Rieger

Division of Ultrastructural Research and Evolutionary Biology,

Institute of Zoology and Limnology,

University of Innsbruck,

Innsbruck, Austria

e-mail: lukas.scharer@uibk.ac.at

Tel.: +43-512-5076170

Fax: +43-512-5072930

L. Schärer

Department of Evolutionary Biology,

Institute of Animal Evolution and Ecology,

University of Münster,

Münster, Germany upregulation of sperm production. It is thus expected that testicular activity is a more sensitive measure of shortterm variation in male allocation than the commonly used static measures.

Keywords Platyhelminthes - Simultaneous hermaphrodite $\cdot$ Sperm competition $\cdot$ Stem cells $\cdot$ Testis size

\section{Introduction}

Current evolutionary theory predicts that the amount of resources a male should allocate to the production of gametes depends on the level and the type of sperm competition it experiences (Parker 1998). Studies aimed at testing this theory have mainly used static measures of male allocation, such as testis weight (Warner and Robertson 1978; Harcourt et al. 1981; Møller 1988a, 1988b; Gage 1994, 1995; Pitnick and Markow 1994a; Petersen and Fischer 1996; Pitnick 1996; Hosken 1997, 1998; Stockley et al. 1997; Simmons et al. 1999; Pitnick et al. 2001; Byrne et al. 2002), testis area (Trouvé et al. 1999; Hosken and Ward 2001; Hosken et al. 2001; Schärer and Ladurner 2003), testis volume (Pitnick and Markow 1994a; Johnston et al. 1998; Schärer and Wedekind 2001; Schärer et al. 2001), ejaculate volume (Møller 1988a, 1988b; Stockley et al. 1997; Schärer and Robertson 1999), ejaculate dry weight (Schärer and Robertson 1999), caloric content of ejaculate (Schärer and Robertson 1999), number of developing sperm in the testis (Pitnick and Markow 1994a; Pitnick 1996; Pitnick et al. 2001), number of mature sperm in the testis (Yund et al. 1997), number of sperm in ejaculate (Pitnick and Markow 1994a; Gage 1995; Pitnick 1996; Stockley et al. 1997; Baur et al. 1998; Schärer and Robertson 1999), spermatophore size (Svärd and Wiklund 1989; Bissoondath and Wiklund 1995, 1996; Baur et al. 1998; Vreys and Michiels 1998), or protein content of spermatophores (Bissoondath and Wiklund 1995, 1996). The choice of these static measures is guided by the rel- 
ative ease with which they can be obtained, rather than by a detailed knowledge of how they relate to resource allocation, which is a dynamic process.

A good analogy for the difference between a dynamic and a static measure is to consider what one can learn about the flow of a river by looking at a photograph of it. The mere presence of water on the photograph is not sufficient to conclude that it is flowing. And, whereas it is generally true that larger rivers have a larger flow, size alone can be a misleading measure. For example, a dam downstream from where we take the photograph would increase the size of the river while preventing the flow. Only by following the fate of a probe can we conclude that there is a flow through the system.

Some studies attempt to address this problem by sequentially mating males to many females and estimating the total amount of sperm transferred as measure of sperm production rate (Pitnick and Markow 1994a, 1994b). However, this approach is potentially confounded by mate choice, with females accepting more sperm from some males than from others (i.e. Pitnick and Markow 1994a). Copulation rate has also been used, but males have been shown to run out of sperm in subsequent matings (Nakatsuru and Kramer 1982; Pitnick and Markow 1994b), and to tailor the number of sperm released in subsequent matings to different conditions (Wedell et al. 2002). So copulation rate alone may also not be a suitable measure for sperm-production rate.

Accurate data on sperm-production rates have only been collected in studies that investigate fertility in the context of contraception, toxicology and animal breeding, and they are limited to birds and mammals (de Reviers and Williams 1984; Cooke et al. 1996; Gupta et al. 1999). Estimation of daily sperm-production rate is often based on the number of specific spermatogenetic stages in testicular homogenates (Amann 1970). This approach is possible in higher vertebrates because vertebrate spermatogenesis is well understood, and because its duration can be accurately estimated. There are only a few studies on vertebrates that examined testis size and daily spermproduction rate in an evolutionary context. A comparative study in primates showed considerable variation in spermatogenic efficiency (i.e. spermatid production per unit of testicular tissue), but this variation was not explained by mating-system differences between the studied species (Wistuba et al. 2003). In contrast, a nine-generation selection experiment for increased testis weight in pigs yielded both higher testis weight, and a higher relative and absolute daily sperm-production rate in the selected line compared to the control line (Johnson et al. 1994; Rathje et al. 1995). Another study showed differences in spermatogenesis, testis morphology, testis size, and daily sperm-production rates in two species of rodents that differ in the level of sperm competition (Peirce and Breed 2001). These studies suggest that factors other than testis weight may be selected by sperm competition, and that dynamic measures need to be considered.

Here we specifically aim at testing the relationship between a static measure of male reproductive allocation, namely testis area, and a dynamic measure, namely cellular activity in the testis. We are not aware of studies that have attempted to evaluate this fundamental assumption that is implicitly made in most empirical tests of spermcompetition theory. Two recent findings allow such an approach in Macrostomum sp., a free-living marine flatworm.

First, we have shown that worms can be experimentally manipulated to produce larger testes by raising them in groups instead of in pairs (Schärer and Ladurner 2003). This approach makes it possible to experimentally vary the static measure testis size in an otherwise homogenous population.

Second, S-phase cells (i.e. cells that are undergoing DNA duplication) in the testis of Macrostomum sp. can be labelled with the thymidine analogue 5-bromo-2'-deoxyuridine (further called BrdU), by incubating living worms in a solution of BrdU in artificial seawater

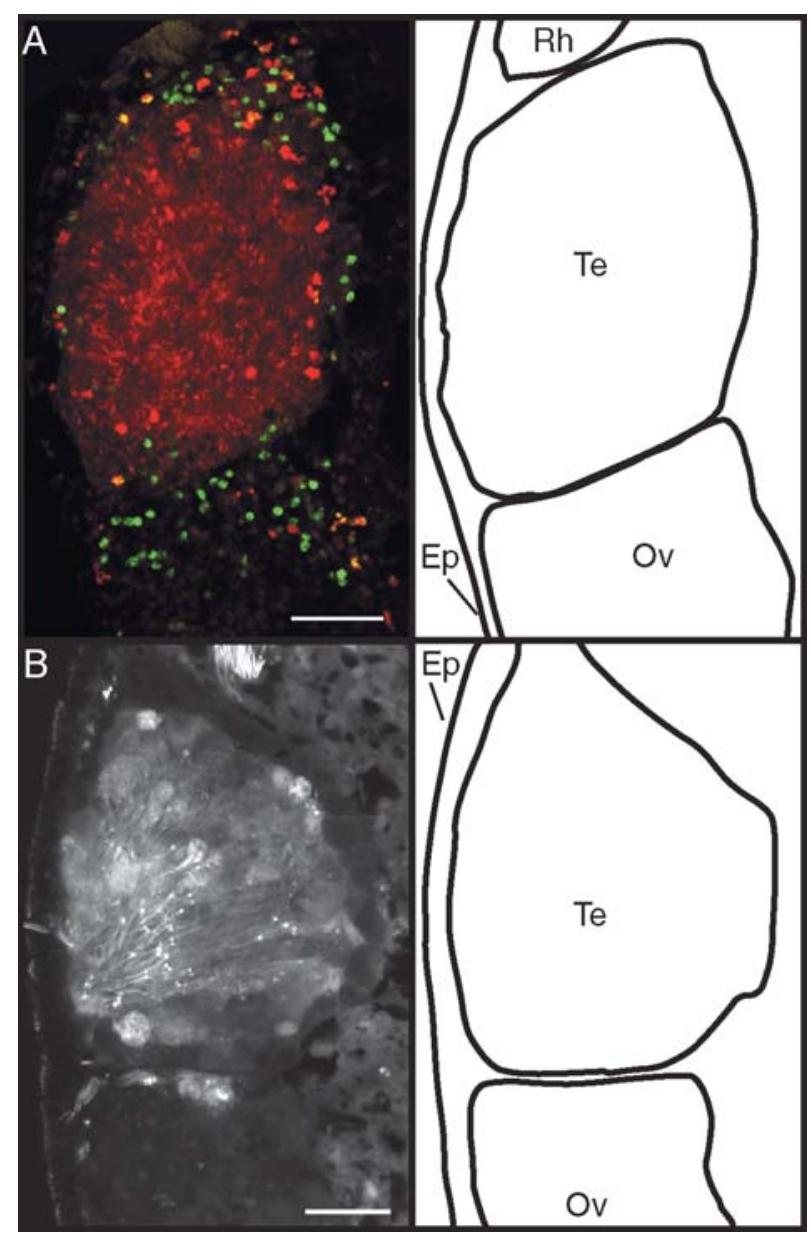

Fig. 1A, B Optical sections through the testis of whole-mount preparations of Macrostomum sp. taken with a Zeiss LSM 510 confocal laser scanning microscope. A Immunocytochemistry: BrdU-labelled stem cells are green and dividing stem cells are red. Note that the red unspecific background stain represents the lumen of the testis. B Vital stain: CellTracker CMFDA stained for $24 \mathrm{~h}$. Note the lighter-grey area represents the lumen of the testis that contains sperm. The line drawings trace the different structures, epidermis $(E p)$, ovary $(O v)$, rhamite glands $(R h)$, testis $(T e)$ 
(Ladurner et al. 2000). S-phase cells in Macrostomum sp. are undifferentiated, potentially totipotent stem cells, and are localised in two lateral bands in a bilaterally symmetric fashion, with a cluster near the anterior parts of the testes and ovaries, respectively (Fig. 1A). Stem cells represent the only proliferating cell population in Macrostomum sp., and all soma and germ cells differentiate from them (Ladurner et al. 2000). It is important to note that the BrdU label is only incorporated in cells that are actively undergoing DNA synthesis and duplication, which are dynamic processes. According to the above analogy, BrdU labelling therefore only occurs "if the river is flowing". The number of BrdU-labelled cells in the testis can thus serve as a dynamic measure of testicular activity.

\section{Methods}

Study animal

Macrostomum sp. (Macrostomorpha, Platyhelminthes) is a freeliving marine flatworm, and a member of the interstitial sand fauna of the northern Adriatic Sea (Ladurner et al. 2000). It is an outcrossing simultaneous hermaphrodite with reciprocal copulation (Schärer et al. 2004), reaches $1.5 \mathrm{~mm}$ in length when fully grown, and has a generation time of 18 days. It is transparent, allowing non-invasive measurement of the paired testes and other internal structures (Schärer and Ladurner 2003). Mass cultures of Macrostomum $\mathrm{sp}$. are maintained in an artificial seawater medium and fed with diatoms (Tyler 1981; Rieger et al. 1988).

\section{Experiment}

The experimental protocol under which the worms were raised for this study is similar to one reported earlier (Schärer and Ladurner 2003), and thus we describe the methods only briefly here. Juvenile worms were collected from mass cultures and placed together in one dish. From there, we randomly distributed worms to one of four group sizes (pairs, triplets, quartets or octets). We achieved random assignment by pipetting individual worms to their assigned well according to a permutation of all the factor combinations, effectively avoiding sequence effects. Manipulation of group size successfully manipulates the number of sperm competitors (Schärer and Ladurner 2003). In order to control for effects of density, groups were placed either in small or large enclosures (i.e. wells of 24- or 6-hole tissue culture plates with 1.5 or $6.0 \mathrm{ml}$ medium, see Schärer and Ladurner 2003 for rationale). Each of the eight factor combinations was replicated six times $(n=48)$. Worms were fed ad libitum and transferred to fresh wells on days 5, 8, 12 and 15.

\section{Morphometry}

On days 18 to 20, we morphometrically determined the area of the worm, the testes, the seminal vesicle (sperm to be used in copulations), and a received sperm score as previously reported (Schärer and Ladurner 2003). Because our design keeps the number of potential sperm donors and sperm recipients constant, more received sperm in larger groups indicates a higher mating rate, and/or that more sperm are transferred per mating. The amount of received sperm should hence indicate the occurrence of sperm competition. A received sperm score was obtained from 107 worms, yielding a median received sperm score for 35 replicates. After measurement, worms were placed in fresh wells together with their original partners and in their original group sizes, and used for immunocytochemistry (see below). One worm was lost, and we excluded 3 worms that were malformed (lack or incomplete formation of copulatory organ), and 3 pair replicates in which only 1 worm survived, yielding morphological data for 184 worms in 45 replicates. Statistical analyses were done as previously reported and results confirmed earlier findings (Schärer and Ladurner 2003). We here only present the novel findings.

\section{Labelling and immunocytochemical localisation}

All labelling steps were done in tissue-culture plates while worms remained with their original partners, and hence also in their original group sizes. Animals were labelled with BrdU (5-bromo2'-deoxyuridine) (Sigma) on day 22 by 30 min incubation in $5 \mathrm{~mm}$ BrdU in medium. To arrest cells in metaphase, worms were then brought to $0.05 \%$ colchicine (Sigma) in medium (two wash steps) and kept in the dark without food. After $16 \mathrm{~h}$, animals were relaxed in a mixture of $7.14 \% \mathrm{MgCl}_{2}$ and medium for $10 \mathrm{~min}$ and then fixed for 60-120 min in 4\% paraformaldehyde in 0.1 M phosphate buffered saline (PBS). Fixed worms were washed twice with PBS, followed by a 60 -min wash with PBS-T (i.e. PBS plus $0.1 \%$ Triton X-100). They were permeated with $0.15 \mu \mathrm{g} / \mathrm{ml}$ Proteinase XIV at $37^{\circ} \mathrm{C}$. Proteinase activity was visually checked and stopped with cooled $0.1 \mathrm{~N} \mathrm{HCl}$. Animals were transferred first to $2 \mathrm{~N} \mathrm{HCl}$ for $1 \mathrm{~h}$ at $37^{\circ} \mathrm{C}$, and then to $1 \mathrm{ml}$ PBS-T (two wash steps) and blocked by adding $1 \mathrm{ml}$ BSA-T for $30 \mathrm{~min}$ (i.e. PBS-T plus $1 \%$ bovine serum albumin). Cells that had incorporated BrdU were localised using a monoclonal mouse anti-BrdU antibody (Sigma) at 1:1,000 dilution in BSA-T overnight at $4^{\circ} \mathrm{C}$. At the same time, we stained with a rabbit anti-phosphorylated histone $\mathrm{H} 3$ antibody (Upstate Biotechnology) at 1:100 dilution. This antibody unspecifically stains the lumen of the testis (see Fig. 1A), and greatly facilitates the assignment of BrdU-positive cells to the testis or other tissues. After 2 wash steps in PBS-T, the secondary goat-anti-mouse FITC- and pig-anti-rabbit TRITC-conjugated antibodies (both DAKO) were applied for $1 \mathrm{~h}$ at room temperature at $1: 100$ and $1: 150$ dilutions in BSA-T, respectively. After two wash steps in PBS-T, animals were individually mounted on randomly numbered microscope slides using Vectashield (Vector Laboratories), thereby allowing further blind analysis.

\section{Quantification of labelled cells}

One testis of one worm per replicate was chosen at random for quantification of testicular activity (i.e. twice the number of BrdUpositive S-phase cells in the chosen testis). BrdU-positive S-phase cells were visualised with a Zeiss LSM 510 confocal laser-scanning microscope with a Plan Neofluoar $\times 40 / 1.3$ oil objective. We made Z-stacks of between 18 and 61 slices (each $512 \times 512$ pixels) of 0.4 or $0.5 \mu \mathrm{m}$ thickness (Fig. 1A), and counted the cells in 3 dimensions using the public domain software Object-Image (available at http://simon.bio.uva.nl/object-image.html). An optical slice from a z-stack of a worm stained for $24 \mathrm{~h}$ with $2 \mu \mathrm{M}$ of the vital stain CellTracker CMFDA (Molecular Probes) in medium shows the anatomy more clearly (Fig. 1B).

\section{Statistical analysis}

Forty of the 45 morphologically measured replicates yielded worms with countable testicular S-phase cells (pairs, $n=7$; triplets, $n=11$; quartets, $n=11$; octets, $n=11$ ). We first checked how testicular activity was related to the mean testis size of worms within a replicate. We use mean testis size because of the fact that we, after the morphometric measurement, placed worms with their original partners and in their original group sizes, and because we therefore could not keep track of the identity of individual worms. We further checked for a correlation between testicular activity and the median received sperm score of the worms of a replicate (pairs, $n=7$; triplets, $n=7$; quartets, $n=8$; octets, $n=9$ ). Such a relationship, if positive, would indicate that active testes are more productive, and that more sperm are transferred when testes are more active. Then, in 
order to see if the variation in testicular activity was attributable to our experimental treatment, we analysed the data with a fully factorial two-way ANCOVA with the group size and enclosure size as factors, the mean time of removal from their wells and the mean size of the worms in the replicate as the covariates, and testicular activity as the dependent variable.

\section{Results}

The average testis area per replicate was strongly correlated to our measure of testicular activity (Fig. 2, Pearson $r=0.57, P<0.001, n=40$ ), showing that larger testes are indeed more active. Moreover, the relationship was approximately linear, so that in Macrostomum sp., testis area is a good measure of male reproductive allocation to the testis. This relationship was not only due to natural variation in male allocation between different worms, because a significant amount of variation in testicular activity was explained by the experimental factor group size (Fig. 3, two-way ANCOVA, full model $r^{2}=0.45$, group size, $F_{3,30}=2.91, P=0.050$; enclosure size, $F_{1,30}=$ 2.06, $P=0.16$; interaction, $F_{3,30}=0.85, P=0.48$; time,

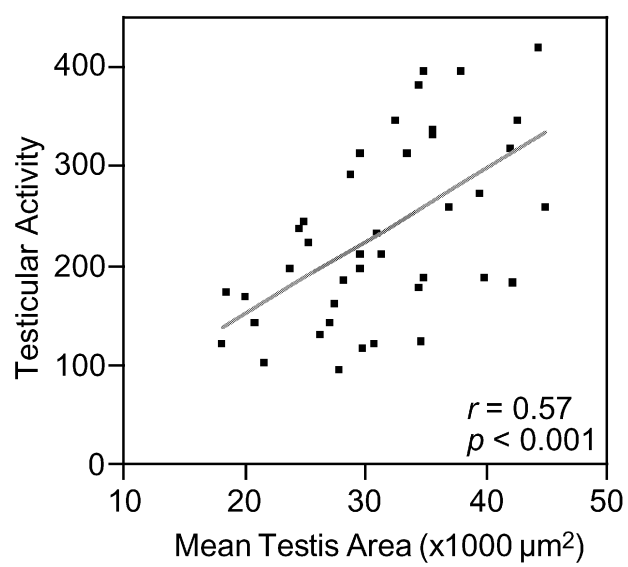

Fig. 2 Correlation between mean testis size per replicate and testicular activity

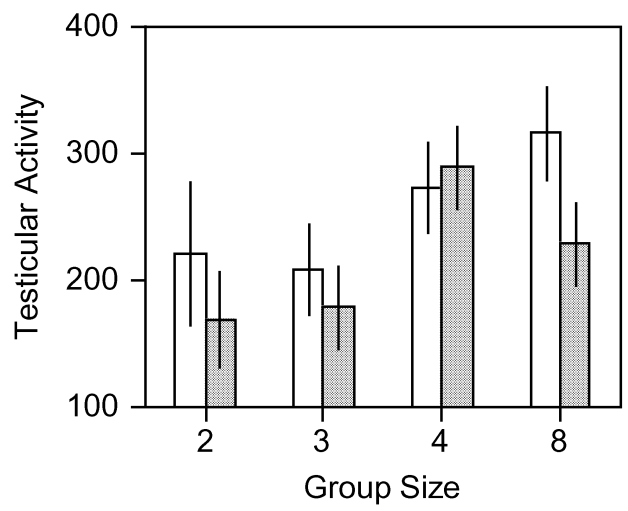

Fig. 3 Effect of group size (x-axis) and enclosure size (white bars, small; grey bars, large) on testicular activity. We show the least squares means $( \pm 1 \mathrm{SE})$ of the two-way ANOVA. See text for statistics

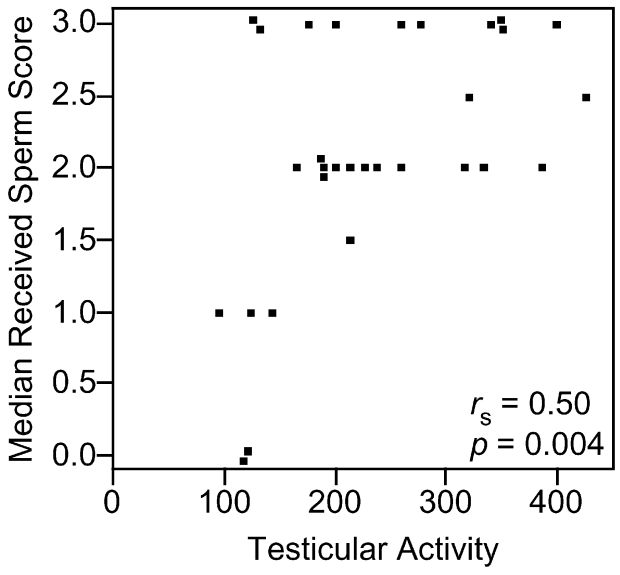

Fig. 4 Correlation between the testicular activity and the median received sperm score per replicate. Some jitter was added to visualise overlapping points

$F_{1,30}=0.006, P=0.94$; worm area, $F_{1,30}=1.50, P=0.22$ ). Thus our experiment successfully manipulated male reproductive allocation. There was also a significant correlation between testicular activity and the median received sperm score per replicate (Fig. 4, Spearman $r_{\mathrm{s}}=0.50, P=0.004, n=31$ ), showing that more sperm are transferred when testicular activity is high.

\section{Discussion}

We show that in the marine flatworm Macrostomum sp., BrdU-labelling can be used to estimate a dynamic measure of male allocation, namely the number of testicular stem cells in S-phase. This measure correlated positively with the mean testis size of worms in a replicate (Fig. 2), thus lending support to the frequently made, but so far untested, assumption that testis size is a useful measure of male reproductive allocation. Moreover, the observed variation in testicular activity was partly explained by the treatments of our experiment (Fig. 3). Testicular activity was significantly higher in worms that grew up in larger groups, but was not affected by enclosure size, and thus the observed differences are not due to density effects (c.f. Schärer and Ladurner 2003). Although the testicular activity in worms from groups of eight in large wells appeared lower, the lack of an interaction effect between group and well size shows that this difference was not significant. Together, this suggests that the cause for the larger testis size observed in larger groups in this worm may be the increased cellular activity in response to the higher mating-group size in larger groups. This is further supported by the fact that the median amount of sperm transferred between worms was also strongly correlated with testicular activity (Fig. 4).

The relationship between testis area and testicular activity was approximately linear, so that in Macrostomum sp., testis area is a good estimate of male allocation. Testis area was estimated while the worms were squeezed between two glass plates in a standardised way (Schärer 
and Ladurner 2003), and hence testis area is expected to represent testis volume well. However, the measure of testis size used here represented an average per replicate, whereas the testicular activity was estimated on the basis of only one randomly chosen worm per replicate. The actual correlation between testis area and testicular activity within individual worms may hence be stronger. Direct measurement of testis size after labelling was not done because the permeation and denaturation steps required for immunocytochemical localisation of $\mathrm{BrdU}$ strongly affect the size of the organs. So although we find support for a linear relationship between testis size and testicular activity, we consider it worthwhile that this relationship be evaluated in other organisms.

Recent work has provided the first experimental evidence for the evolution of male reproductive traits under different levels of sexual selection. Experimental removal of sexual selection, and hence removal of sperm competition, did lead to changes in testis size in two species of Diptera (Hosken and Ward 2001; Hosken et al. 2001; Pitnick et al. 2001; Snook 2001). However, sperm-production efficiency can differ between closely related species (Peirce and Breed 2001) and such a difference can appear as a correlated response to directional selection on testis size (Rathje et al. 1995). In other words, the number of sperm that can be produced by a given amount of testicular tissue may be under selection with, for example, sperm competition selecting for a more efficient testis. This suggests that it would be interesting to determine if sperm-production parameters other than testis size are affected by such experimental evolution experiments.

Furthermore, in mammals, the testis is not only the site of sperm production, but is also involved in the production of male hormones. A recent study on capybara revealed that, although dominant males had larger testes, the testis size was more closely correlated to the size of the androgen-dependent scent glands than to the amount of spermatogenic tissue in the testis (Moreira et al. 1997). Although scent glands probably also represent male reproductive investment, the possibility for multiple functions of the testis calls for an independent assessment of the relationship between testis size and sperm production.

Finally, rapid modulation of stem-cell activity in response to feeding after starvation has previously been observed in Macrostomum sp. (Nimeth et al. 2004). Worms that were fed after 30 days of starvation showed a 24 -fold increase in the number of S-phase cells after just $2 \mathrm{~h}$ of feeding. This indicates that the activity of the stemcell population is highly dynamic. Increased stem-cell proliferation in the testis of Macrostomum sp. should be one of the first steps in the upregulation of sperm production. Indeed, it has been postulated that the stem cells of flatworms have receptors for a variety of neuropeptides (Baguña et al. 1989). Stem cells may thus be able to react to sensory stimuli that occur inside the worm (such as, for example, the fill grade of the seminal vesicle) or stimuli that occur in the environment of the worms (such as dissolved substances in the water). BrdU-labelling is thus a suitable tool to uncover the sensory basis of the phe- notypically plastic response to increased mating-group size (Schärer and Ladurner 2003). It should be a powerful tool to illuminate the physiological, developmental and biochemical changes that accompany modulation in male allocation in response to sperm competition and sexual selection (Snook 2001).

Acknowledgements We would like to thank Martina Hrouda, Monika Mahlknecht, Katharina Nimeth and Willi Salvenmoser for help in the laboratory, Bernd Pelster for access to the laser scanning microscope, and the NIH-Image mailing list community, particularly Norbert Vischer, for invaluable help regarding image analysis and for providing an import macro for Zeiss LSM 510 files. Jacob Koella, Nico Michiels, Peter Sandner, Solveig Schjørring, Dita Vizoso, and two anonymous referees provided helpful discussion and comments on the manuscript. During this study, L.S. was supported by an IHP-fellowship (SNF, Switzerland) and a LiseMeitner-fellowship (FWF, Austria), and P.L. by an APART fellowship (Austrian Academy of Science). The study was further supported by grant P15204 (FWF, Austria) to R.M.R. Animal experimentation was carried out in accordance with Austrian legal and ethical standards.

\section{References}

Amann RP (1970) Sperm production rates. In: Johnson AD, Gomes WR, Vandermark NL (eds) The testis, vol I. Academic, New York, pp 433-482

Baguña J, Saló E, Romero R (1989) Effects of activators and antagonists of neuropeptides substance $\mathrm{P}$ and substence $\mathrm{K}$ on cell proliferation in planarians. Int J Dev Biol 33:261-264

Baur B, Locher R, Baur A (1998) Sperm allocation in the simultaneously hermaphroditic land snail Arianta arbustorum. Anim Behav 56:839-845

Bissoondath CJ, Wiklund C (1995) Protein content of spermatophores in relation to monandry/polyandry in butterflies. Behav Ecol Sociobiol 37:365-371

Bissoondath CJ, Wiklund C (1996) Effect of male history and body size on ejaculate size and quality in two polyandrous butterflies, Pieris napi and Pieris rapae (Lepidoptera: Pieridae). Funct Ecol 10:457-464

Byrne PG, Roberts JD, Simmons LW (2002) Sperm competition selects for increased testes mass in Australian frogs. J Evol Biol 15:347-355

Cooke PS, Zhao YD, Hansen LG (1996) Neonatal polychlorinated biphenyl treatment increases adult testis size and sperm production in the rat. Toxicol Appl Pharmacol 136:112-117

Gage MJG (1994) Associations between body size, mating pattern, testis size and sperm lengths across butterflies. Proc R Soc Lond Ser B 258:247-254

Gage MJG (1995) Continuous variation in reproductive strategy as an adaptive response to population density in the moth Plodia interpunctella. Proc R Soc Lond Ser B 261:25-30

Gupta G, Maikhuri JP, Dwivedi AK, Dhar JD, Setty BS (1999) Changes in daily sperm production rate in rats under the influence of a potent antispermatogenic agent, CDRI 84/35. Contraception 59:401-404

Harcourt AH, Harvey PH, Larson SG, Short RV (1981) Testis weight, body weight and breeding system in primates. Nature 293:55-57

Hosken DJ (1997) Sperm competition in bats. Proc R Soc Lond Ser B 264:385-392

Hosken DJ (1998) Testes mass in megachiropteran bats varies in accordance with sperm competition theory. Behav Ecol Sociobiol 44:169-177

Hosken DJ, Ward PI (2001) Experimental evidence for testes size evolution via sperm competition. Ecol Lett 4:10-13

Hosken DJ, Garner TWJ, Ward PI (2001) Sexual conflict selects for male and female reproductive characters. Curr Biol 11:489-493 
Johnson RK, Eckardt GR, Rathje TA, Drudik DK (1994) 10 generations of selection for predicted weight of testes in swinedirect response and correlated response in body-weight, backfat, age at puberty, and ovulation rate. J Anim Sci 72:19781988

Johnston MO, Das B, Hoeh WR (1998) Negative correlation between male allocation and rate of self-fertilization in a hermaphroditic animal. Proc Natl Acad Sci 95:617-620

Ladurner P, Rieger RM, Baguña J (2000) Spatial distribution and differentiation potential of stem cells in hatchlings and adults in the marine platyhelminth Macrostomum sp.: a bromodeoxyuridine analysis. Dev Biol 226:231-241

Møller AP (1988a) Ejaculate quality, testis size and sperm competition in primates. J Hum Evol 17:479-488

Møller AP (1988b) Testis size, ejaculate quality and sperm competition in birds. Biol J Linn Soc 33:273-283

Moreira JR, Macdonald DW, Clarke JR (1997) Correlations of testis mass in capybaras (Hydrochaeris hydrochaeris): dominance assurance of sperm competition. J Zool 241:457-463

Nakatsuru K, Kramer DL (1982) Is sperm cheap? Limited male fertility and female choice in the lemon tetra (Pisces, Characidae). Science 216:753-755

Nimeth KT, Mahlknecht M, Mezzanato A, Peter R, Rieger R, Ladurner P (2004) Stem cell dynamics during growth, feeding and starvation in the basal flatworm Macrostomum sp. (Platyhelminthes). Dev Dyn 230:91-99

Parker GA (1998) Sperm competition and the evolution of ejaculates: towards a theory base. In: Birkhead TR, Møller AP (eds) Sperm competition and sexual selection. Academic, London, pp 3-54

Peirce EJ, Breed WG (2001) A comparative study of sperm production in two species of Australian arid zone rodents (Pseudomys australis, Notomys alexis) with marked differences in testis size. Reproduction 121:239-247

Petersen CW, Fischer EA (1996) Intraspecific variation in sex allocation in a simultaneous hermaphrodite: the effect of individual size. Evolution 50:636-645

Pitnick S (1996) Investment in testes and the cost of making long sperm in Drosophila. Am Nat 148:57-80

Pitnick S, Markow TA (1994a) Large-male advantages associated with costs of sperm production in Drosophila hydei, a species with giant sperm. Proc Natl Acad Sci USA 91:9277-9281

Pitnick S, Markow TA (1994b) Male gametic strategies: sperm size, testes size, and the allocation of ejaculate among successive mates by the sperm-limited fly Drosophila pachea and its relatives. Am Nat 143:785-819

Pitnick S, Miller GT, Reagan J, Holland B (2001) Males' evolutionary responses to experimental removal of sexual selection. Proc R Soc Lond Ser B 268

Rathje TA, Johnson RK, Lunstra DD (1995) Sperm production in boars after 9 generations of selection for increased weight of testis. J Anim Sci 73:2177-2185

Reviers M de, Williams JB (1984) Testis development and production of spermatozoa in the cockerel (Gallus domesticus). In:
Cunningham FJ, Lake PE, Hewitt D (eds) Reproductive biology of poultry. British Poultry Science, Harlow, pp 183-202

Rieger RM, Gehlen M, Haszprunar G, Holmlund M, Legniti A, Salvenmoser W, Tyler S (1988) Laboratory cultures of marine Macrostomida (Turbellaria). Fortschr Zool 36:523

Schärer L, Ladurner P (2003) Phenotypically plastic adjustment of sex allocation in a simultaneous hermaphrodite. Proc R Soc Lond Ser B 270:935-941

Schärer L, Robertson DR (1999) Sperm and milt characteristics and male versus female investment in the Caribbean reef fish, Thalassoma bifasciatum. J Fish Biol 55:329-343

Schärer L, Wedekind C (2001) Social situation, sperm competition, and sex allocation in a simultaneous hermaphrodite parasite, the cestode Schistocephalus solidus. J Evol Biol 14:942-953

Schärer L, Karlsson LM, Christen M, Wedekind C (2001) Sizedependent sex allocation in a simultaneous hermaphrodite parasite. J Evol Biol 14:55-67

Schärer L, Joss G, Sandner P (2004) Mating behaviour of the marine turbellarian Macrostomum sp.: these worms suck. Mar Biol. DOI 10.1007/s002270041314

Simmons LW, Tomkins JL, Hunt J (1999) Sperm competition games played by dimorphic male beetles. Proc R Soc Lond Ser B 266:145-150

Snook RR (2001) Conflict, kindness and chicanery. Curr Biol 11:R337-R341

Stockley P, Gage MJG, Parker GA, Møller AP (1997) Sperm competition in fishes: the evolution of testis size and ejaculate characteristics. Am Nat 149:933-954

Svärd L, Wiklund C (1989) Mass and production rate of ejaculates in relation to monandry/polyandry in butterflies. Behav Ecol Sociobiol 24:395-402

Trouvé S, Jourdane J, Renaud F, Durand P, Morand S (1999) Adaptive sex allocation in a simultaneous hermaphrodite. Evolution 53:1599-1604

Tyler S (1981) Development of cilia in embryos of the turbellarian Macrostomum. Hydrobiologia 84:231-239

Vreys C, Michiels NK (1998) Sperm trading by volume in a hermaphroditic flatworm with mutual penis intromission. Anim Behav 56:777-785

Warner RR, Robertson DR (1978) Sexual patterns in the labroid fishes of the western Caribbean. I: The wrasses (Labridae). Smithson Contrib Zool 254:1-27

Wedell N, Gage MJG, Parker GA (2002) Sperm competition, male prudence and sperm-limited females. Trend Ecol Evol 17:313320

Wistuba J, Schrod A, Greve B, Hodges JK, Aslam H, Weinbauer GF, Luetjens CM (2003) Organization of seminiferous epithelium in primates: relationship to spermatogenic efficiency, phylogeny, and mating system. Biol Reprod 69:582-591

Yund PO, Marcum Y, Stewart-Savage J (1997) Life-history variation in a colonial ascidian: broad-sense heritabilities and tradeoffs in allocation to asexual growth and male and female reproduction. Biol Bull 192:290-299 